\title{
A three-factor structure of cognitive functioning among carriers and non-carriers of autosomal-dominant Alzheimer's disease
}

\author{
Edmarie Guzmán-Vélez ${ }^{\star}, a$, Sehily Jaimes ${ }^{\star}, a$, Daniel C. Aguirre-Acevedob,c, Daniel J. \\ Norton $^{\mathrm{a}}$, Kathryn V. Papp ${ }^{\mathrm{d}, \mathrm{e}}$, Rebecca Amariglio ${ }^{\mathrm{d}, \mathrm{e}}$, Dorene Rentz ${ }^{\mathrm{d}, \mathrm{e}}$, Ana Baena ${ }^{\mathrm{C}}$, Eliana \\ Henao $^{c}$, Victoria Tiradoc ${ }^{c}$ Claudia Muñoz ${ }^{c}$, Margarita Giraldo ${ }^{c}$, Reisa A. Sperling ${ }^{\text {d,e }}$, \\ Francisco Loperac $^{\mathrm{c}}$, Yakeel T. Quiroz ${ }^{\mathrm{a}, \mathrm{c}, \mathrm{e}}$ \\ aDepartment of Psychiatry, Massachusetts General Hospital, Harvard Medical School, Boston, \\ MA, USA \\ bGrupo Académico de Epidemiología Clínica, School of Medicine, University of Antioquia, \\ Medellín, Colombia \\ 'Grupo de Neurociencias de Antioquia, School of Medicine, University of Antioquia, Medellín, \\ Colombia \\ ${ }^{\mathrm{d} C e n t e r}$ for Alzheimer Research and Treatment, Department of Neurology, Brigham and Women's \\ Hospital, Boston, MA, USA \\ eDepartment of Neurology, Massachusetts General Hospital, Harvard Medical School, Boston, \\ MA, USA
}

\section{Abstract}

Objective: There is a need to find cognitive markers that can help identify individuals at risk for Alzheimer's disease (AD), and that can be used to reliably measure cognitive decline. We tested whether a theoretically driven three-factor structure would characterize cognitive functioning in individuals who are genetically-determined to develop AD due to a mutation in Presenilin-1 (PSEN1) gene. We also examined whether these factors could distinguish cognitively unimpaired PSEN1 mutation carriers from age-matched non-carrier family members.

Method: 1395 cognitively unimpaired members of a Colombian kindred with the PSEN1 E280A mutation were included in the study. A confirmatory factor analysis examined the fit of the threefactor model comprising episodic memory (MMSE memory recall, CERAD-COL Word list recall and Constructional praxis recall), executive function (Phonemic fluency and WCST perseverative errors), and psychomotor processing speed (TMT-A and WAIS-III Digit Symbol).

\footnotetext{
First corresponding author: Yakeel T. Quiroz, PhD, Assistant Professor, Harvard Medical School, Departments of Psychiatry and Neurology, Massachusetts General Hospital, 149 13th Street, Suite 10.014, Boston, MA 02129, Phone (617) 643-5944; Fax: (617) 726-5760; yquiroz@mgh.harvard.edu. Second corresponding author: Francisco Lopera, MD, Director, Grupo de Neurociencias de Antioquia, Universidad de Antioquia, Sede de Investigaciones Universitarias, Medellin, Colombia. Francisco.lopera@gna.org.co. These authors contributed equally to this manuscript.

The following authors have no conflict of interest to report: EGV, SJ, DCA, DJN, RA, AB, EH, VT, CM, MG, FL, and YTQ. KP has served as a consultant for Biogen Idec. DR has served as a consultant for Eli Lilly, Biogen Idec, and Lundbeck Pharmaceuticals and serves as a member of the Scientific Advisory Board for Neurotrack. RAS is a site principal investigator or coinvestigator for Avid, Bristol-Myers Squibb, Pfizer, and Janssen Alzheimer Immunotherapy clinical trials.
} 
Results: The three-factor model provided an excellent fit for all participants ( $p=.24$;RMSEA $=$. 01 ). Further, the episodic memory ( $p=.0004, d=0.25$ ) and executive functioning ( $p=.001, d=0.18$ ) factors distinguished cognitively unimpaired carriers from non-carriers. The episodic memory factor provided the earliest indication of preclinical cognitive decline at 35 years of age, nine years before individuals' estimated age of clinical onset.

Conclusions: The three theoretically derived cognitive factors provide a reliable measure of cognition and may be useful for the early detection of $\mathrm{AD}$, as well as for measuring disease progression. However, longitudinal studies are needed to confirm that these factors can be used to track the progression of cognitive decline in preclinical AD.

\section{Keywords}

confirmatory factor analysis; cognitive factors; preclinical Alzheimer's disease; episodic memory; executive function; processing speed

\section{INTRODUCTION}

Alzheimer's disease (AD) is a progressive, neurodegenerative disorder with no cure at this time. Recent research shows that neuropathological changes associated with AD (e.g., amyloid plaques, neurofibrillary tangles, abnormal brain activity) begin decades before the onset of symptoms, in what is now known as the preclinical stage of the disease [1-8]. These biological changes eventually result in cognitive decline that impact the individual's ability to function independently. It has been suggested that therapies administered in the preclinical stage of $\mathrm{AD}$ have the potential to slow or reverse the trajectory of AD [9-10]; however, accurately identifying individuals in that early stage of $\mathrm{AD}$ remains a challenge.

Although the most common form of AD is characterized by late-onset (after age 65) of symptoms, researchers have identified several autosomal-dominant mutations that lead to early-onset ( $<65$ years old) familial AD (ADAD), including mutations in the Presenilin-1 (PSEN1), Presenilin-2 (PSEN2), and Amyloid Precursor Protein (APP) genes. Individuals who carry these mutations are virtually fated to develop AD later in life, and can be identified with near perfect accuracy through genetic testing. Therefore, studying individuals with ADAD provides researchers a unique opportunity to understand preclinical AD-related changes decades before the onset of symptoms.

Individuals with preclinical ADAD often first exhibit subtle changes in episodic memory, followed by a progressive decline in other cognitive functions, including executive functioning, language and processing speed [11-13]. For instance, Aguirre-Acevedo and colleagues (2016) reported that individuals with ADAD showed worse scores on the CERAD Word List Recall compared to age-matched controls up to 12 years before the age of expected clinical symptom onset. Although this individual test appears to be useful for identifying individuals at risk for $\mathrm{AD}$ very early on, it and other challenging tests like it, may not be effective for tracking progression of cognitive decline over time due to "“floor" effects [14]. 
One way to address these limitations is by using composite scores [15]. In addition to reducing "floor" and "ceiling" and practice effects, composite scores have a more symmetric distribution with better adjustment to normal distribution than individual tests. Additionally, composite scores may decrease type I errors when making multiple comparisons.

Factor analyses reduce the number of related cognitive variables into a lower number of unobserved variables called factors. A prior study examining the factor structure of multiple cognitive tests that are frequently administered in AD studies found that these were organized into three primary factors in cognitively healthy older adults: episodic memory, executive functioning and processing speed [16]. Notably, that study found that the episodic memory factor was significantly associated with amyloid burden, a key biological marker of $\mathrm{AD}$, suggesting that these factors could also be useful in understanding the relationship between $\mathrm{AD}$ neuropathology and cognition. With this in mind, we sought to determine whether a three-factor structure characterizes cognitive functioning in preclinical ADAD, by studying a unique and large extended family with a PSEN1 mutation from Colombia. Individuals from this kindred typically develop mild cognitive impairment (MCI) at a median age of 44 years (+/- 2years 95\% CI) and dementia at $49(+/-2$ years $95 \% \mathrm{CI})$ years of age [11], and show AD-related neuropathological changes, such as amyloid burden and phosphorylated tau, more than a decade before the onset of clinical symptoms [1-2]. Further, we examined whether these three cognitive factors could distinguish individuals who will develop AD (PSEN1 mutation carriers) from age matched non-carrier family members. Given that decline in episodic memory is one of the earliest changes seen in individuals with ADAD, we hypothesized that cognitively unimpaired PSEN1 mutation carriers would have worse performance on the episodic memory factor, and that performance on this factor would distinguish carriers from non-carriers.

\section{MATERIAL AND METHODS}

\section{Participants}

Participants were recruited from a large extended family in Colombia, with a high prevalence of the PSEN1 E280A mutation. A total of 1395 cognitively unimpaired members were included; 233 were PSEN1 E280A mutation carriers and 1162 were non-carrier family members. All participants were blind to their own genetic status. Only those with a negative history of psychiatric disorders, illiteracy, stroke, epilepsy, traumatic brain injury, kidney failure, human immunodeficiency syndrome, or substance abuse were included in the study. Demographic data are presented in Table 1.

This research study was approved by the ethics research committee of the University of Antioquia, Colombia. Written informed consent was obtained from all participants prior to initiation of any study procedures and data collection in accordance with the ethics committee. Researchers were blind to the genetic status of the cognitively unimpaired subjects during data collection. 


\section{Neuropsychological Measures}

A comprehensive cognitive test battery was administered to all participants, according to standard procedures in a single session. Tests included the Mini Mental Status Exam (MMSE) [17], Trail-Making Test A (TMT-A) [18], Wechsler Adult Intelligence Scale-Third Edition (WAIS-III) Digit Symbol subtest [19], phonemic fluency (FAS) [20], Wisconsin Card Sorting Test (WCST) [21], and the Spanish-Colombian version of the Consortium to Establish a Registry for Alzheimer's Disease (CERAD-COL) test battery. The CERADCOL has been previously validated with this population [22] and has been shown to be a useful screening tool for individuals with MCI and dementia in ADAD [12]. Of note, the tests that were chosen for this confirmatory factor analysis were based on the neuropsychological battery used in Colombia to follow up these families. Tests from that battery were compared to the ones used for a prior study with cognitively healthy older adults [16]. The versions of the tests that we used, when not identical to the ones employed by Hedden et al., were chosen because they were the only ones available or validated for a Spanish-speaking population at the time of administration. All tests were administered in Spanish, participant's first and primary language. Table 1 presents cognitive data for unimpaired PSEN1 E280A mutation carriers and non-carriers.

\section{Cognitive Factors}

Cognitive subtests were grouped in three theoretically defined factors, including episodic memory, executive functioning and processing speed.

Episodic Memory.-The episodic memory factor was defined as short-term memory recall, and delayed verbal and non-verbal free recall. This factor included the subtests of MMSE memory recall, the CERAD word list delayed recall, and the CERAD constructional praxis delayed recall.

Processing Speed.-This factor was defined as the total time to complete a task requiring visual attention, the TMT-A, and the total number of items completed within a limited amount of time on the WAIS-III Digit Symbol subtest, a perceptual-motor speed task.

Executive Function.-This factor was defined as controlled-word generation, as measured by letter fluency (FAS), and self-monitoring abilities, as measured by the total number of perseverative errors on the WCST.

\section{Statistical Analysis}

Statistical analyses were conducted using MPlus software-version 7.31 [23]. We conducted a confirmatory factor analysis to evaluate our three-dimensional model. Seven variables of interest, as described above, were included in the confirmatory factor analysis. The covariance among observed variables was estimated for all participants. The asymptotic distribution free estimation method as used as proposed by Browne (1984) [24]. We used the root mean square error of approximation (RMSEA), the Tucker-Lewis index (TLI), and comparative fit index (CFI), to capture the relative goodness of fit. We considered a RMSEA below 0.06 , TLI values greater than .95 , and a CFI equal or above 0.90 to be indicators of 
good fit [25]. We also report the chi-square statistic $(\chi 2)$ as a measure of model fit. A nonsignificant chi-square was considered an index of a well-fitting model ( $\mathrm{p}$ 2.05). Based on the modification indices, we accounted for the correlations between residuals in MMSE memory recall and CERAD word list delayed recall, and between CERAD constructional praxis delayed recall and TMT-A, to obtain a better fit of the model.

We subsequently tested whether cognitively unimpaired PSEN1 E280A mutation carriers and non-carriers significantly differed in episodic memory, executive functioning, or processing speed. Neuropsychological test scores were each transformed into standardized scores (z-scores). A composite score was created for each cognitive domain by adding the standardized score of tests corresponding to a cognitive function. Of note, scores for the TMT-A and WCST perseveration errors were inverted so that a positive score represented a better performance. The composite scores were transformed into a standard score and then into a $\mathrm{T}$ score $($ mean $=50$, Standard Deviation $=10)$. We then conducted a one-way analysis of covariance (ANCOVA), controlling for the effects of educational attainment, to compare the scores for each cognitive domain between the cognitively unimpaired PSEN1 mutation carriers and the non-carriers. Effect sizes were calculated using Cohen's $d$. Confidence intervals of the difference between groups are also reported. All $t$ tests used a significance threshold of $p<0.05$; we used the Bonferroni correction procedure to correct for multiple comparisons using the three factors. Therefore, group differences were considered statistically significant when $p<0.017$.

Finally, longitudinal studies have shown that the rate of cognitive decline in preclinical AD is not a constant linear process but that it increases after a certain change point many years before the onset of clinical symptoms [12,26]. Given that age is predictive of clinical onset in PSEN1 E280A mutation carriers, cross-sectional assessments across a wide age range in this well-defined cohort are perhaps analogous to what might be expected from the assessment of longitudinal trajectories of cognitive change. Therefore, a change point approach can be used to provide an estimate of when cognitive decline is likely to begin in this population. With this in mind, we used a linear regression model to estimate the crosssectional relationship between age and cognitive function. Cognitively impaired individuals were added to the sample to conduct these analyses for a total of 1443 impaired and cognitively unimpaired participants (252 carriers and 1191 non-carriers). The change point or onset of cognitive decline was estimated with the approach taken by Hall and colleagues (2000). Age was centered at 20 years in order to provide an interpretation of the constant in the model. Fifty models were adjusted by varying the change point annually between the ages of 18 and 60 years. We then used the likelihood approach to compare the models based on the goodness-of-fit index as the Bayesian information criterion (BIC) [26, 27]. The lowest Bayesian information criterion was accepted as appropriate.

\section{RESULTS}

\section{Confirmatory Factor Analysis}

Fit for the three-factor model in cognitively unimpaired PSEN1 E280A mutation carriers and non-carriers was acceptable $\left(\chi^{2}(8)=10,4, p=.239\right.$; CFI $=.999$; TLI $=.998$; RMSEA $=.014)$. Figure 1 shows the three-factor model. 


\section{Cognitive differences between carriers and non-carriers}

Compared to non-carriers, cognitively unimpaired carriers had worse performance on the episodic memory factor $(\mathrm{F}(1,24)=12.60, p=.0004, d=0.25,95 \% \mathrm{CI}[-0.39,-0.114])$, and executive functioning $(\mathrm{F}(1,24)=6.07, \mathrm{p}=.001, \mathrm{~d}=0.18,95 \% \mathrm{CI}[-0.31,-0.036])$. No significant differences were observed between cognitively unimpaired PSEN1 carriers and non-carriers on processing speed $(\mathrm{F}(1,24)=1.58, p=.209, d=-0.09,95 \%$ CI $[-0.05$, $0.23])$. A sensitivity analysis was conducted with the factor scores instead of composite scores. Findings were consistent with the ones reported above.

\section{Change point of cognitive decline in PSEN1 carriers}

Mutation carriers had a change point at the age of 35 years for the episodic memory factor (Figure 2A), and a later change point for the executive functioning (36 years) and processing speed factors (38 years) (Figures 2B and 2C).

\section{DISCUSSION}

The present study tested a theoretically driven factor structure in a large and homogeneous group of cognitively unimpaired PSEN1 mutation carriers and non-carrier family members. The resulting confirmatory factor analysis provided an excellent fit for all participants. These findings confirmed that the seven cognitive tests examined in this study can be grouped into three different factors in ADAD that measure episodic memory, executive function or processing speed. We then evaluated whether these cognitive factors distinguished cognitively unimpaired individuals at genetic risk for AD from age-matched controls. Recent studies have reported verbal and visual memory decline in PSEN1 mutation carriers and older adults during the preclinical stage of $\mathrm{AD}[2,12,28-30]$. However, this is the first study to examine cognitive changes in carriers using factors of discrete cognitive domains. Differences in the episodic memory factor were evident between cognitively unimpaired PSEN1 mutation carriers and non-carriers, with carriers exhibiting worse cognitive performance. Further, the episodic memory factor seems to be an early indicator of cognitive decline at 35 years of age, almost a decade before the estimated median age of clinical onset for the kindred. Similarly, the executive function factor also distinguished cognitively unimpaired carriers from non-carriers with an estimated decline at 36 years of age. The processing speed factor did not distinguish groups.

Our findings show that the episodic memory and executive functioning factors are sensitive to the early cognitive changes that occur in the preclinical stage of ADAD. These findings support prior research, in both late-onset sporadic and early-onset autosomal-dominant AD, suggesting that memory systems are affected very early in the disease process, followed by progressive impairment of other brain systems and cognitive abilities, such as executive functions [5, 11, 31-39]. In fact, our findings show that decline in executive functions follow decline in episodic memory early in the disease process. This is consistent with prior studies with older adults at risk for AD [21, 36], as well as with a prior study with PSEN1 E280A carriers showing decline in an executive function test, approximately two years after mutation carriers show significant memory decline [12]. These three factors are thus useful descriptive markers of cognitive functioning in the preclinical stage of AD. They may also 
prove to be useful for tracking progression of AD-related cognitive decline. During the trajectory of $\mathrm{AD}$, individual cognitive tests may present ceiling effects (higher values) at preclinical AD stages and floor effects as the disease advances. This limits the use of individual tests for statistical modeling in longitudinal studies, which are very important for further understanding the progression of the disease and the efficacy of interventions. Thus, using these factor scores overtime instead of individual test scores may help reduce "floor" and "ceiling" effects. Using factor scores also minimizes practice effects and the influence of measurement error, all of which have important implications for clinical trials and treatment outcome research. Further, although total cognitive scores, such as the CERAD total score, provide an early indicator of cognitive decline in PSEN1 mutation carriers at 34 years of age [12], this score only provides information about a conglomerate of cognitive functions. Instead, the three factors can be used to measure the progression of distinct cognitive functions to better characterize preclinical cognitive changes associated with AD.

The current study has several strengths. First, we tested a large number of individuals with a single AD-causing mutation, and compared them with their family members, with similar sociocultural background, without the mutation. This is important given that demographic variables such as socioeconomic status, and occupation, among others, have been shown to impact cognitive functioning [12, 40]. Given this similarity across groups, it is unlikely that demographic variables that were not included in the analyses account for the differences observed between groups in cognitive functioning. Further, we only compared three factors, which allowed us to reduce the amount of multiple comparisons and increase our power.

This study also has limitations. Although the factor structure of the cognitive tests is consistent with that of older adults at risk for AD reported by Hedden and colleague (2012), it is still uncertain whether our findings can be generalized to those at risk for late-onset AD, the most common form of $\mathrm{AD}$, as well as to other genetic mutations. Further, there were not enough measures of language or visuospatial functioning to have those factors included in the current analysis. It would be important to include those factors in future studies since they may provide complimentary information in the characterization of preclinical $\mathrm{AD}$, as well as include newer tests that may be more sensitive to subtle cognitive changes in AD. Finally, the small effect sizes of the group differences may limit the clinical application of the factor scores. Nonetheless, these may useful for tracking disease progression, from preclinical to clinical stages.

In summary, studying individuals who are genetically predisposed to develop AD provides a unique opportunity to examine changes that occur years before the onset of dementia. This in turn may aid with the development of effective interventions aimed at preventing or delaying the onset of AD symptomatology [9-10]. We confirmed that the seven tests evaluated in this study can be grouped into three cognitive factors (episodic memory, processing speed, and executive functioning) in cognitively unimpaired individuals with ADAD. Performance on these factors may help with the early identification of individuals at risk for sporadic $\mathrm{AD}$. Longitudinal studies and in comparison to older adults at risk for late onset $\mathrm{AD}$, as measured by biomarkers, are needed to substantiate these findings and better understand the ability of these cognitive factors to track progression from preclinical stage to dementia. 


\section{ACKNOWLEDGEMENTS}

The authors thank the PSEN1 Colombian families for contributing their valuable time and effort, without which this study would not have been possible.

This research was supported by the National Institute of Health- Office of the Director (DP5OD019833 [YTQ]), MGH ECOR Clafin Distinguished Scholar Award [YTQ], MGH Physician/Scientist Development Award [YTQ], and COLCIENCIAS (Colombia;111565741185 [FLR]).

\section{REFERENCES}

[1]. Edmonds EC, Bangen KJ, Delano-Wood L, Nation DA, Furst AJ, Salmon DP, Bondi MW; Alzheimer's Disease Neuroimaging Initiative (2016) Patterns of Cortical and Subcortical Amyloid Burden across Stages of Preclinical Alzheimer's Disease. J Int Neuropsychol Soc 22, 978-990. [PubMed: 27903335]

[2]. Fleisher AS, Chen K, Quiroz YT, Jakimovich LJ, Gutierrez Gomez M, Langois CM, Langbaum JB, Roontiva A, Thiyyagura P, Lee W, Ayutyanont N, Lopez L, Moreno S, Muñoz C, Tirado V, Acosta-Baena N, Fagan AM, Giraldo M, Garcia G, Huentelman MJ, Tariot PN, Lopera F, Reiman EM. (2015). Associations between biomarkers and age in the presenilin 1 E280A autosomal dominant Alzheimer disease kindred: a cross-sectional study. JAMA Neurol 72, 316324. [PubMed: 25580592]

[3]. Morris JC (2005) Early-stage and preclinical Alzheimer disease. Alzheimer Dis Assoc Disord 19, 163-165. [PubMed: 16118535]

[4]. Quiroz YT, Ally BA, Celone K, McKeever J, Ruiz-Rizzo AL, Lopera F, Stern CE, Budson AE (2011) Event-related potential markers of brain changes in preclinical familial Alzheimer disease. Neurology 77, 469-475 [PubMed: 21775732]

[5]. Quiroz YT, Budson AE, Celone K, Ruiz A, Newmark R, Castrillón G, Lopera F, Stern CE (2010) Hippocampal hyperactivation in presymptomatic familial Alzheimer's disease. Ann Neurol 68, 865-875. [PubMed: 21194156]

[6]. Quiroz YT, Stern CE, Reiman EM, Brickhouse M, Ruiz A, Sperling RA, Lopera F, Dickerson BC (2013) Cortical atrophy in presymptomatic Alzheimer's disease presenilin 1 mutation carriers. J Neurol Neurosurg Psychiatry 84, 556-561. [PubMed: 23134660]

[7]. Sperling RA, Aisen PS, Beckett LA, Bennett DA, Craft S, Fagan AM, Iwatsubo T, Jack CR Jr, Kaye J, Montine TJ, Park DC, Reiman EM, Rowe CC, Siemers E, Stern Y, Yaffe K, Carrillo MC, Thies B, Morrison-Bogorad M, Wagster MV, Phelps CH. (2011). Toward defining the preclinical stages of Alzheimer's disease: recommendations from the National Institute on AgingAlzheimer's Association workgroups on diagnostic guidelines for Alzheimer's disease. Alzheimers Dement, 7, 280-292. [PubMed: 21514248]

[8]. Sutphen CL, Jasielec MS, Shah AR, Macy EM, Xiong C, Vlassenko AG, Benzinger TL, Stoops EE, Vanderstichele HM, Brix B, Darby HD, Vandijck ML, Ladenson JH, Morris JC, Holtzman DM, Fagan AM (2015) Longitudinal cerebrospinal fluid biomarker changes in preclinical Alzheimer disease during middle age. JAMA Neurol 72, 1021-1042. [PubMed: 26167811]

[9]. Cummings JL, Doody R, Clark C (2007) Disease-modifying therapies for Alzheimer disease: Challenges to early intervention. Neurology 69, 1622-1634. [PubMed: 17938373]

[10]. Palmer BW (2016) Sensitive and Specific Preclinical Identification of Alzheimer Disease: A key to novel intervention development. Am J Geriatr Psychiatry 24, 914-915.

[11]. Acosta-Baena N, Sepulveda-Falla D, Lopera-Gomez CM, Jaramillo-Elorza MC, Moreno S, Aguirre-Acevedo DC, Saldarriaga A, Lopera F (2011) Pre-dementia clinical stages in presenilin 1 E290A familial early-onset Alzheimer's disease: a retrospective cohort study. Lancet Neurol 10, 213-220. [PubMed: 21296022]

[12]. Aguirre-Acevedo DC, Lopera F, Henao E, Tirado V, Muñoz C, Giraldo M, Bangdiwala SI, Reiman EM, Tariot PN, Langbaum JB, Quiroz YT, Jaimes (2016) Cognitive decline in a Colombian kindred with autosomal dominant Alzheimer disease: a retrospective cohort study. JAMA Neurol 73, 431-438. [PubMed: 26902171] 
[13]. Arango-Lasprilla JC, Cuetos F, Valencia C, Uribe C, Lopera F (2007) Cognitive changes in the preclinical phase of familial Alzheimer's disease. J Clin Exp Neuropsychol 29, 892-900. [PubMed: 17852592]

[14]. Barth S, Schönknecht P, Pantel J, Schröder J (2005) Mild cognitive impairment and Alzheimer's disease: an investigation of the CERAD-NP test battery. Fortschr Neurol Psychiatr 73, 568-576. [PubMed: 16217697]

[15]. Morris MC, Evans DA, Hebert LE, Bienias JL (1999) Methodological issues in the study of cognitive decline. Am J Epidemiol 149, 789-793. [PubMed: 10221314]

[16]. Hedden T, Mormino EC, Amariglio RE, Younger AP, Schultz AP, Becker JA, Buckner RL, Johnson KA, Sperling RA, Rentz DM (2012) Cognitive profile of amyloid burden and white matter hyperintensities in cognitively normal older adults. Journal Neurosci 32, 16233-16242.

[17]. Tombaugh TN, McIntyre NJ (1992) The Mini-Mental State Examination: A Comprehensive Review. J Am Geriatr Soc 40, 922-935. [PubMed: 1512391]

[18]. Reitan RM (1958) Validity of the Trail Making Test as an indicator of organic brain damage. Percept Mot Skills 8, 271-276.

[19]. Joya S, Edith K, Fein D (2004) Speed and memory in the WAIS-III Digit Symbol Coding subtest across the adult lifespan. Arch Clin Neuropsychol 19, 759-767. [PubMed: 15288329]

[20]. Tombaugh TN, Kozak J, Rees L (1999) Normative data stratified by age and education for two measures of verbal fluency: FAS and animal naming. Arch Clin Neuropsychol 14,167-77. [PubMed: 14590600]

[21]. Hazlett KE, Figueroa CM, Nielson KA (2015) Executive functioning and risk for Alzheimer's disease in the cognitively intact: Family history predicts Wisconsin Card Sorting Test performance. Neuropsychology 29, 582-591. [PubMed: 25621538]

[22]. Aguirre-Acevedo DC, Gomez RD, Moreno S, Henao-Arboleda E, Motta M, Muñoz C, Arana A, Pineda DA, Lopera F (2007). Validity and reliability of the CERAD-Col neuropsychological battery [in Spanish]. Rev Neurol 45, 655-660. [PubMed: 18050096]

[23]. Muthén LK, Muthén BO (1998-2012) Mplus User's Guide. Seventh Edition.

[24]. Browne MW (1984) Asymptotically distribution-free methods for the analysis of covariance structures. Br J Math Stat Psychol 37, 62-83. [PubMed: 6733054]

[25]. Hu L, Bentler PM (1999) Cutoff criteria for fit indexes in covariance structure analysis: Conventional criteria versus new alternatives. Structural Equation Modeling 6, 1-55.

[26]. Hall CB, Lipton RB, Sliwinski M, Stewart WF (2000) A change point model for estimating the onset of cognitive decline in preclinical Alzheimer's disease. Stat Med 19, 1555-1566. [PubMed: 10844718]

[27]. van den Hout A, Muniz-Terrera G, Matthews FE (2013) Change point models for cognitive tests using semi-parametric maximum likelihood. Comput Stat Data Anal 57, 684-698. [PubMed: 23471297]

[28]. Matias-Guiu JA, Cabrera-Martín MN, Curiel RE, Valles-Salgado M, Rognoni T, Moreno-Ramos T, Carreras JL, Loewenstein DA, Matías-Guiu J (2018) Comparison between FCSRT and LASSIL to Detect Early Stage Alzheimer's Disease. J Alzheimer's Dis 61, 103-111. [PubMed: 29125488]

[29]. Mowrey WB, Lipton RB, Katz MJ, Ramratan WS, Loewenstein DA, Zimmerman ME, Buschke H (2018) Memory Binding Test Predicts Incident Dementia: Results from the Einstein Aging Study. J Alzheimer's Dis 62, 293-304. [PubMed: 29439336]

[30]. Parra MA, Abrahams S, Logie RH, MéNdez LG, Lopera F, Della Sala S (2010) Visual short-term memory binding deficits in familial Alzheimer's disease. Brain 133, 2702-2713. [PubMed: 20624814]

[31]. Bastin C, Salmon E (2014) Early neuropsychological detection of Alzheimer's disease. Eur J of Clin Nutr 68, 1192-1199. [PubMed: 25182019]

[32]. Sperling RA, Dickerson BC, Pihlajamaki M, Vannini P, LaViolette PS, Vitolo OV, Hedden T, Becker JA, Rentz DM, Selkoe DJ, Johnson KA. (2010). Functional Alterations in Memory Networks in Early Alzheimer's Disease. Neuromolecular Med 12, 27-43. [PubMed: 20069392]

[33]. Almkvist O, Rodriguez-Vietez E, Thordardottir S, Amberla K, Axelman K, Basun H, KinhultStåhlbom A, Lilius L, Remes A, Wahlund LO,Viitanen M, Lannfelt L, Graff C (2017) Predicting 
cognitive decline across four decades in mutation carriers and non-carriers in autosomaldominant Alzheimer's disease. J Int Neuropsychol Soc 23, 195-203 [PubMed: 28079014]

[34]. Bateman RJ, Xiong C, Benzinger TL, Fagan AM, Goate A, Fox NC, Marcus DS, Cairns NJ, Xie X, Blazey TM, Holtzman DM, Santacruz A, Buckles V, Oliver A, Moulder K, Aisen PS, Ghetti B, Klunk WE, McDade E, Martins RN, Masters CL, Mayeux R, Ringman JM, Rossor MN, Schofield PR, Sperling RA, Salloway S, Morris JC; Dominantly Inherited Alzheimer Network (2012) Clinical and biomarker changes in dominantly inherited Alzheimer's disease. N Engl J Med 367, 795-804. [PubMed: 22784036]

[35]. Chhatwal J, Schultz AP, Johnson K, Benzinger TL, Jack C Jr, Ances BM, Sullivan CA, Salloway SP, Ringman JM, Koeppe RA, Marcus DS, Thompson P, Saykin AJ, Correia S, Schofield PR, Rowe CC, Fox NC, Brickman AM, Mayeux R, McDade E, Bateman R, Fagan AM, Goate AM, Xiong C, Buckles VD, Morris JC, Sperling RA (2013) Impaired default network functional connectivity in autosomal dominant Alzheimer disease. Neurology 81, 736-44. [PubMed: 23884042]

[36]. Hartley SL, Handen BL, Devenny D, Mihaila I, Hardison R, Lao PJ, Klunk WE, Bulova P, Johnson SC, Christian BT (2017). Cognitive decline and brain amyloid- $\beta$ accumulation across 3years in adults with Down syndrome. Neurobiol Aging 58, 68-76. [PubMed: 28715661]

[37]. Hof PR, Giannakopoulos P, Bouras C (1996) The neuropathological changes associated with normal brain aging. Histol Histopathol 11, 1075-1088. [PubMed: 8930649]

[38]. Shah D, Praet J, Latif Hernandez A, Höfling C, Anckaerts C, Bard F, Morawski M, Detrez JR, Prinsen E, Villa A, De Vos WH, Maggi A, D’Hooge R, Balschun D, Rossner S, Verhoye M, Van der Linden A (2016) Early pathologic amyloid induces hypersynchrony of BOLD resting-state networks in transgenic mice and provides an early therapeutic window before amyloid plaque deposition. Alzheimers Dement 12, 964-976. [PubMed: 27107518]

[39]. Storand M, Balota DA, Aschenbrenner AJ, Morris JC (2014) Clinical and psychological characteristics of the initial cohort of the dominantly inherited Alzheimer network. Neuropsychology 28, 19-29. [PubMed: 24219606]

[40]. Stern Y (2012). Cognitive reserve in ageing and Alzheimer's disease. Lancet Neurol 11, 10061012. [PubMed: 23079557] 


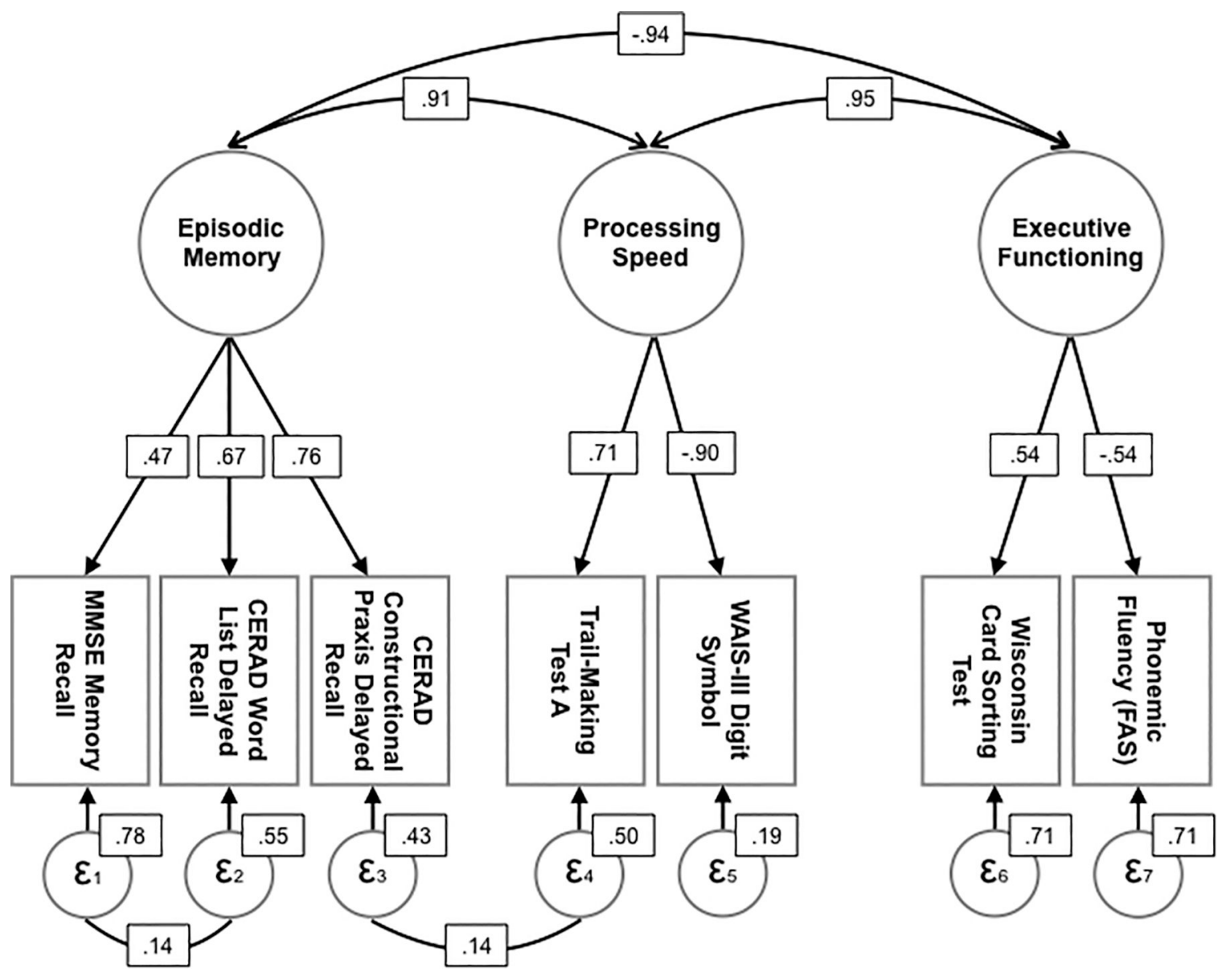

Figure 1.

Three-dimensional model for the Confirmatory Factor Analysis with cognitively unimpaired PSEN1 E280A mutation carriers and non-carriers

Note. Confirmatory factor analysis of cognitive domains in cognitively unimpaired PSEN1 mutation carriers $(\mathrm{n}=233)$ and non-carriers $(\mathrm{n}=1162)$. The model has good fit $\left(\chi^{2}(9)=\right.$ 13.52, $p=0.14$; CFI = .993; TLI =.985; RMSEA = .019). Larger circles represent latent variables and rectangles represent indicators. Straight lines indicate path weights. Curved arrows represent correlations between factors. 

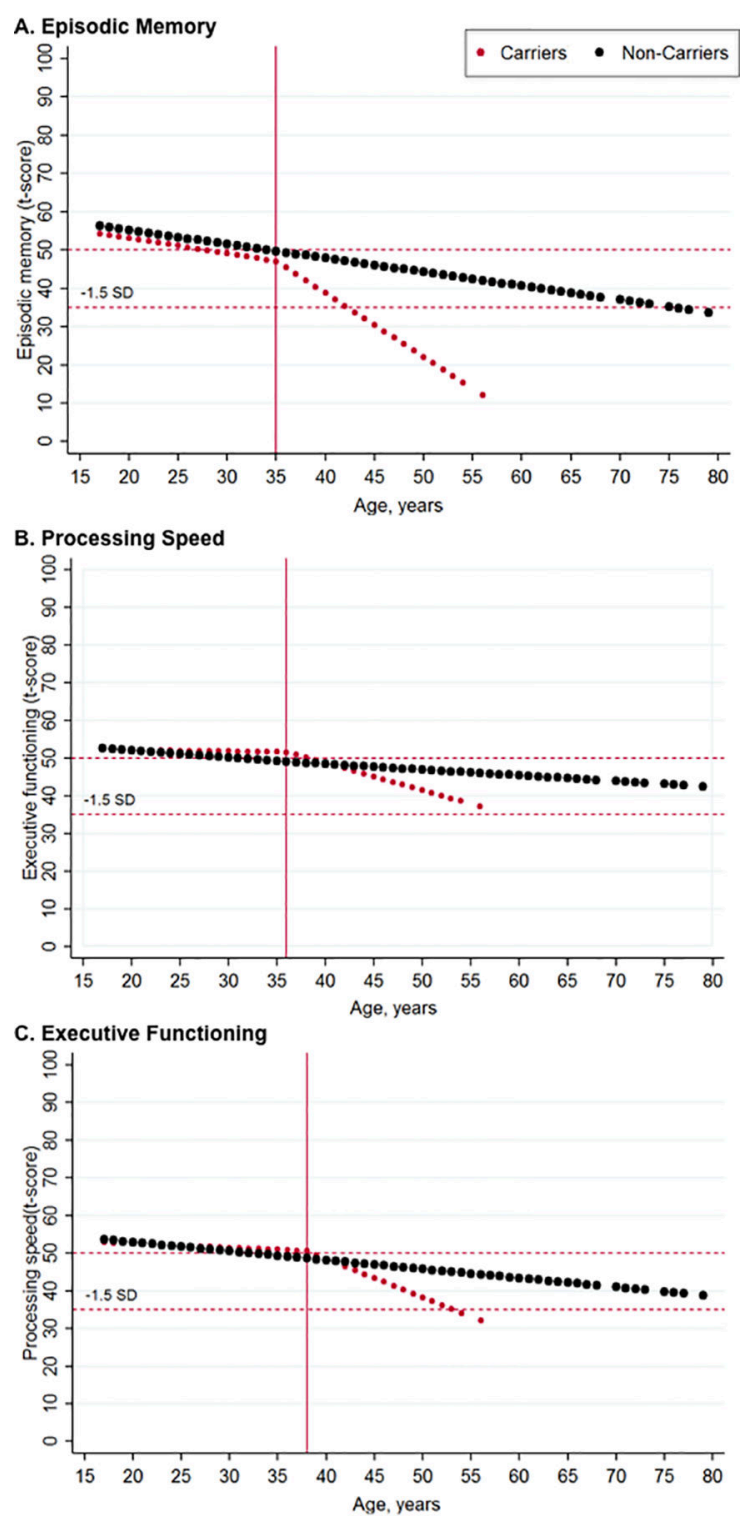

Figure 2.

Estimated course of cognitive decline for PSEN1 E280A carriers and non-carriers.

Note. Figures represent the estimated age of change point for A) episodic memory, B) processing speed, and C) executive function, in PSEN1 E280A mutation carriers $(\mathrm{n}=252)$ and non-carriers $(\mathrm{n}=1191)$. The red dotted line represents the estimated change point in PSEN1 carriers, and the black line represents the estimated change point in non-carriers. 
Table 1.

Demographic and cognitive data

\begin{tabular}{|c|c|c|c|}
\hline Variable & $\begin{array}{c}\text { Cognitively Unimpaired Non-carriers } \\
\text { Mean (SD) }\end{array}$ & $\begin{array}{c}\text { Cognitively Unimpaired Carriers } \\
\text { Mean (SD) }\end{array}$ & $p$-value \\
\hline Age range & $32.0(12.6)$ & $27.7(9.5)$ & $<.001$ \\
\hline $17-21$ years & 255 & 77 & \\
\hline $22-27$ years & 287 & 58 & \\
\hline $28-38$ years & 318 & 68 & \\
\hline$\geq 39$ years & 302 & 30 & \\
\hline Sex, No. & & & .22 \\
\hline Female & 654 & 121 & \\
\hline Male & 508 & 112 & \\
\hline Education & $8.3(4.4)$ & $7.8(3.8)$ & .11 \\
\hline \multicolumn{4}{|l|}{ Episodic Memory Tests } \\
\hline MMSE DR & $2.5(0.8)$ & $2.4(0.9)$ & .02 \\
\hline Word List DR & $6.1(1.7)$ & $5.7(2.0)$ & .01 \\
\hline Constructional Praxis DR & $8.4(2.6)$ & $8.0(2.9)$ & .10 \\
\hline \multicolumn{4}{|l|}{ Processing Speed Tests } \\
\hline Trail-Making Test A & $73.5(48.3)$ & $72.7(43.0)$ & .40 \\
\hline WAIS-III Digit Symbol & $43.2(18.6)$ & $43.1(18.9)$ & .49 \\
\hline \multicolumn{4}{|l|}{ Executive Functioning Tests } \\
\hline WCST Perseverative Errors & $20.2(8.2)$ & $19.1(7.4)$ & .03 \\
\hline Phonemic Fluency (FAS) & $27.0(10.1)$ & $27.9(9.5)$ & .88 \\
\hline
\end{tabular}

Note. p-value was defined by an independent samples $t$ test for PSEN1 unimpaired carriers vs non-carrier family members. DR $=$ Delayed Recall; MMSE = Mini-Mental State Examination; WAIS-IV = Wechsler Adult Intelligence Scale-Fourth Edition; WCST = Wisconsin Card Sorting Test. Of note, scores for the TMT-A and WCST perseveration errors were inverted so that a positive score represents a better performance. 